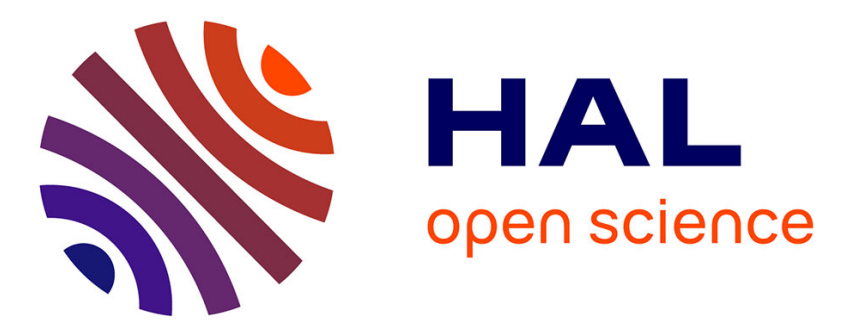

\title{
Neuroprotective role of intermittent fasting in senescence-accelerated mice P8 (SAMP8)
}

M. Tajes, J. Gutierrez-Cuesta, J. Folch, D. Ortuño-Sahagun, E. Verdaguer, A. Jiménez, F. Junyent, A. Lau, A. Camins, M. Pallàs

\section{- To cite this version:}

M. Tajes, J. Gutierrez-Cuesta, J. Folch, D. Ortuño-Sahagun, E. Verdaguer, et al.. Neuroprotective role of intermittent fasting in senescence-accelerated mice P8 (SAMP8). Experimental Gerontology, 2010, 45 (9), pp.702. 10.1016/j.exger.2010.04.010 . hal-00615111

HAL Id: hal-00615111

https://hal.science/hal-00615111

Submitted on 18 Aug 2011

HAL is a multi-disciplinary open access archive for the deposit and dissemination of scientific research documents, whether they are published or not. The documents may come from teaching and research institutions in France or abroad, or from public or private research centers.
L'archive ouverte pluridisciplinaire HAL, est destinée au dépôt et à la diffusion de documents scientifiques de niveau recherche, publiés ou non, émanant des établissements d'enseignement et de recherche français ou étrangers, des laboratoires publics ou privés. 


\section{Accepted Manuscript}

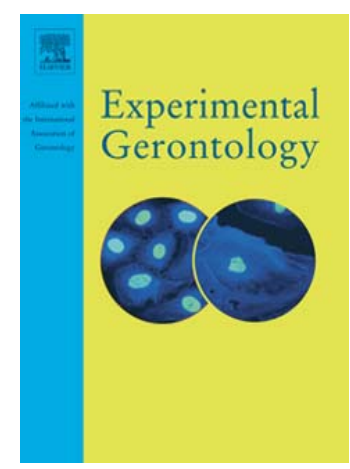

Neuroprotective role of intermittent fasting in senescence-accelerated mice P8 (SAMP8)

M. Tajes, J. Gutierrez-Cuesta, J. Folch, D. Ortuño-Sahagun, E. Verdaguer, A. Jiménez, F. Junyent, A. Lau, A. Camins, M. Pallàs

PII:

S0531-5565(10)00188-9

DOI:

doi: 10.1016/j.exger.2010.04.010

Reference:

EXG 8747

To appear in: $\quad$ Experimental Gerontology

Received date: 25 December 2009

Revised date: $\quad 23$ April 2010

Accepted date: $\quad 29$ April 2010

Please cite this article as: Tajes, M., Gutierrez-Cuesta, J., Folch, J., Ortuño-Sahagun, D., Verdaguer, E., Jiménez, A., Junyent, F., Lau, A., Camins, A., Pallàs, M., Neuroprotective role of intermittent fasting in senescence-accelerated mice P8 (SAMP8), Experimental Gerontology (2010), doi: 10.1016/j.exger.2010.04.010

This is a PDF file of an unedited manuscript that has been accepted for publication. As a service to our customers we are providing this early version of the manuscript. The manuscript will undergo copyediting, typesetting, and review of the resulting proof before it is published in its final form. Please note that during the production process errors may be discovered which could affect the content, and all legal disclaimers that apply to the journal pertain. 
Neuroprotective role of intermittent fasting in senescence-accelerated mice P8 (SAMP8)

M. Tajes ${ }^{1,2}$, J. Gutierrez-Cuesta ${ }^{1,2}$, J. Folch $^{2,3}$, D. Ortuño-Sahagun ${ }^{4}$, E. Verdaguer $^{1,2}$, A.

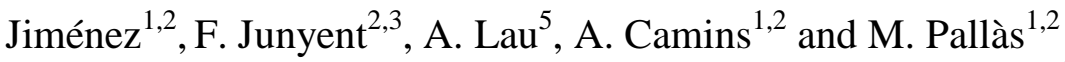

${ }^{1}$ Unitat de Farmacologia i Farmacognòsia Facultat de Farmàcia, Institut de Biomedicina (IBUB), Universitat de Barcelona. Nucli Universitari de Pedralbes. 08028 Barcelona, Spain.

${ }^{2}$ Centros de Investigación Biomédica en Red de Enfermedades Neurodegenerativas (CIBERNED).

${ }^{3}$ Unitat de Bioquimica, Facultat de Medicina i Ciències de la Salut, Universitat Rovira i Virgili. C./ St. Llorenç 2143201 Reus (Tarragona), Spain

${ }^{4}$ Laboratorio de Desarrollo y Regeneración Neural, Instituto de Neurobiología, Departamento de Biología Celular y Molecular, C.U.C.B.A, Universidad de Guadalajara, Guadalajara, Jalisco, Mexico.

${ }^{5}$ Department of Neurosciences, Case Western Reserve University, Cleveland, Ohio, USA

Correspondence to: Mercè Pallàs, $\mathrm{PhD}$

Unitat de Farmacologia i Farmacognòsia Facultat de Farmàcia

Universitat de Barcelona. Nucli Universitari de Pedralbes. E-08028 Barcelona, Spain e-mail: pallas@ub.edu 


\begin{abstract}
Dietary interventions have been proposed as way to increase lifespan and improve health. The senescence-accelerated prone 8 (SAMP8) mice have a shorter lifespan and show alterations in the central nervous system. Moreover, this mouse strain shows decreased sirtuin 1 protein expression and elevated expression of the acetylated targets NFKB and FoxO1, which are implicated in transcriptional control of key genes in cell proliferation and cell survival, in reference to control strain, SAMR1. After eight weeks of intermittent fasting, sirtuin 1 protein expression was recovered in SAMP8. This recovery was accompanied by a reduction in the two acetylated targets. Furthermore, SAMP8 showed a lower protein expression of BDNF and HSP70 while intermittent fasting re-established normal values. The activation of JNK and FoxO1 were also reduced in SAMP8 mice subjected to an IF regimen, compared with control SAMP8. Our findings provide new insights into the participation of sirtuin 1 in ageing and point to a potential novel application of this enzyme to prevent frailty due to ageing processes in the brain.
\end{abstract}

Key words: ageing, neurodegeneration, NFאB, ADAM10, BDNF, sirtuin 1 


\section{INTRODUCTION}

A reduced calorie intake extends the lifespan and increases resistance to age-related diseases in rodents and monkeys, as well as improving the health of overweight humans (Martin et al., 2006) by enhancing cardiovascular and brain functions and decreasing several risk factors for coronary artery disease and stroke. For example, a reduced calorie diet lowers blood pressure and enhances insulin sensitivity. In addition, rodents on a low calorie diet show improved cardiovascular stress adaptation and increased heart rate variability. Moreover, experimental rodent models of myocardial infarction and stroke on an intermittent fasting (IF) regimen exhibit increased resistance of heart and brain cells to ischemic injury. The beneficial effects of IF and caloric restriction (CR) result from at least two mechanisms, namely reduced oxidative damage and increased cellular stress resistance (Calabrese et al., 2008). In the epidemiology of neurodegenerative diseases, the incidence of sporadic Parkinson's disease (PD) and Alzheimer's disease (AD) is correlated with multiple genetic factors, diet and social behavior (Mattson et al., 2002). High calorie diets are associated with the risk of AD, and it has been proposed that a low calorie diet may afford protection against PD and AD (Mattson, 2003). A possible link between CR and AD was proposed after observations of the potential benefits of sirtuin 1 activation on $\mathrm{AD}$ symptoms and progression (Westphal et al., 2007).

Sirtuin 1 is an NAD-dependent deacetylase that not only deacetylates histone but also several proteins and substrates modifying its action or activity. Amongst the nonhistone cellular substrates of sirtuin 1 are the tumor suppressor $\mathrm{p} 53$, the transcription factor NF- $\mathrm{KB}$ and the FOXO family of transcription factors. All the above are involved in transcriptional control of key genes in cell proliferation and cell survival. Sirtuin 1 also deacetylates nuclear receptor peroxisome-proliferator activated receptor- $\gamma(\operatorname{PPAR} \gamma)$ and its transcriptional co-activator PPARc coactivator- $\alpha$ (PGC- $\alpha$ ), which regulate a wide range of metabolic activities in muscle, adipose tissues and liver (Rodgers et al., 2005; Salminen et al., 2008; Smith, 2002). Recent findings also suggest that some of the beneficial effects of IF on the cardiovascular system and the brain are mediated by brain-derived neurotrophic factor signalling (BDNF) in the brain (Duan et al., 2001). In reference to implication of sirtuin 1 in neurodegeneration, SIRT1 may regulate aging and neurodegenerative processes, including protein aggregation, stress responses 
(FOXO,p53,Ku70), mitochondrial dysfunction (PGC-1 $\alpha$ ), and inflammation (NF- $\kappa \mathrm{B}$ and LXR). Considerable evidence indicates that the sirtuin 1 pathway regulates cell survival mechanisms and that it rescues proteins in a number of neurodegenerative conditions (Hipkiss, 2007). For example, deacetylation of FoxO1 by sirtuin 1 promotes the expression of p27/kip1 and manganese superoxide dismutase. This observation implicates sirtuin 1 in decreased oxidative stress and in cell cycle control (Wang et al., 2007). Qin et al, 2006 report that the predicted attenuation of $\beta$-amyloid content in the brain during $\mathrm{CR}$ can be reproduced in mouse neurons in vitro by manipulating cellular sirtuin 1 expression/activity through mechanisms involving the regulation of the serine/threonine Rho kinase ROCK1, known in part for its role in the inhibition of the non-amyloidogenic $\alpha$-secretase (ADAM10) processing of the amyloid precursor protein.

Senescence-accelerated mice (SAM) were originally generated from AKR/J mice (Takeda, 1999). SAMP, Senescence-accelerated prone mice, strains show normal development and maturity of reproductive function, followed by an early manifestation of senescence-related phenotypes indicative of accelerated ageing, including loss of hair, lordokyphosis, periophthalmic disorders, loss of activity and shortened life. Early changes in SAMP8 (between 3 and 5 months old) have been reported, thereby confirming the accelerated senescence of this strain (Canudas et al., 2005; Tajes et al., 2008). The long-lived mice SAMR1, littermates of age-accelerated mice, do not show senescence-related phenotypes and are commonly used as a control strain. It has been suggested that restriction of calorie intake is crucial for the prevention of learning and memory deficits in different animal models (Komatsu et al., 2008).

Collectively, data indicate that long-term reductions in energy intake during adult life protect the brain against diseases associated with ageing. Thus, energy restriction should be considered, together with exercise and cognitive enrichment, as an approach for reducing the risk of $\mathrm{AD}$. A better understanding of the cellular and molecular mechanisms by which reduced calorie intake affects brain cells may lead to novel preventive and therapeutic strategies for extending life expectancy and for tackling neurodegenerative diseases. Here we studied a murine model of senescence (SAMP8) under IF to delineate some of the pathways activated by this dietary strategy and elucidate their possible role in the prevention of senescence-related brain impairment 
and the onset of AD. The pathway of sirtuin 1, a critical sinalling cascade involved in cell proliferation and survival, was of the main interest.

\section{Materials and methods}

\section{Mice}

Weaned male SAMP8 and senescence accelerated-resistant 1 (SAMR1) mice were housed under controlled temperature and light conditions $\left(21-24{ }^{\circ} \mathrm{C}, 12\right.$-hour $(\mathrm{h})$ light/12-h dark cycle) in an animal facility at the University of Barcelona. Animal care and experimental procedures were performed in accordance with the Guidelines for Animal Experimentation established by the "Generalitat de Catalunya" (Spain), with the approval of the University of Barcelona's Animal Care and Use Committee (CEEAUB). Four-week-old mice were divided into 4 groups of 10 males per group. The groups were assigned to dietary regimens as follows: SAMR1 ad libitum (SAMR1); SAMP8 ad libitum (SAMP8); SAMR1 intermittent fasting (IF-SAMR1); and SAMP8 intermittent fasting (IF-SAMP8). All mice ate standard mouse food pellets (Harlam standard diet). Mice on the IF diet were deprived of food for $24 \mathrm{~h}$ every other day. During all procedures, food intake and body weight was monitored.

\section{Brain isolation and Western blot analysis}

After 8 weeks of the IF protocol, mice were killed by decapitation between 9:00 and 12:00 $\mathrm{h}$ after a feeding day. The brain was immediately removed and dissected into cortex and hippocampus. Each brain part was frozen in powdered dry ice and maintained at $-80{ }^{\circ} \mathrm{C}$ until use.

Tissues were homogenized in lysis buffer containing protease inhibitors (Cocktail II, Sigma, St Louis, MO, USA). The protein concentration in the tissue samples was determined using the BCA protein assay kit (Pierce, Rockford, IL, USA). 20 micrograms of protein was separated by SDS-PAGE (8-12\%) and transferred to nitrocellulose membranes. The membranes were blocked in 5\% non-fat milk for $1 \mathrm{~h}$ at room temperature followed by an overnight incubation at $4{ }^{\circ} \mathrm{C}$ with antibodies against sirtuin 1, p-FoxO1, FoxO1, p-GSK3ß Tyr ${ }^{216}$, GSK3ß, p-JNK, JNK, BDNF (1:1000, from Cell Signaling, Beverly, MA, USA), p-tau $\operatorname{Ser}^{199}$ (1:1000; Biosource-Invitrogen Corp., Carlsbad, USA)), HSP70 (1:1000, Stressgen, San Diego, CA, USA), ADAM 10 
(1:1000 from ABCAM, Cambridge, UK) and $\beta$-actin (1:20000 in blocking buffer, from Neomarkers, Fremont, CA, USA). The membranes were washed and incubated with secondary antibodies for $1 \mathrm{~h}$ at room temperature. Protein bands were visualized using a chemiluminescence detection kit (Amersham Corp., Arlington Heights, IL, USA). Band intensities were quantified by densitometric analysis, and values were normalized to actin expression.

\section{Co-immunoprecipitation}

For the co-immunoprecipitation experiment, total protein $(50 \mu \mathrm{g})$ was brought to a final volume of $0.5 \mathrm{~mL}$ with $\mathrm{PBS}+2 \% \mathrm{BSA}$ and incubated with $4 \mu \mathrm{g}$ of anti-FoxO1 total for $6 \mathrm{~h}$ at $4^{\circ} \mathrm{C}$. Immunocomplexes were captured by incubating the samples with protein A-agarose suspension overnight at $4^{\circ} \mathrm{C}$ on a rocker platform. After microcentrifugation, the pellet was washed in $60 \mu \mathrm{l}$ of SDS-PAGE sample buffer and boiled for $5 \mathrm{~min}$ at $100^{\circ} \mathrm{C}$. An aliquot of the supernatant was subjected to electrophoresis in $10 \%$ SDSPAGE and immunoblotted with antibody against acetyl-lysine (1:1000, from Cell Signaling).

\section{Extraction and Quantification of Total RNA}

Total RNA isolation was carried out by means of the NucleoSpin ${ }^{\circledR}$ RNA II kit, following the manufacturer's instructions. Briefly, cell culture medium was removed and cells rinsed with PBS and lysed directly in the culture dish by adding lysis buffer containing $\beta$ mercaptoethanol. For each preparation, one NucleoSpin ${ }^{\circledR}$ RNA II column Macherey-Nagel (Macherey-Nagel GmbH \& Co. KG, Düren, Germany) was placed in a 2-mL centrifuge tube and the lysate was loaded. After centrifugation, $30 \mathrm{~s}$ at $8,000 \mathrm{~g}$, the column was desalted and loaded with $95 \mu \mathrm{L}$ of DNAse I reaction mixture. After 15 min of digestion at room temperature, the RNA was eluted from the column and recovered in $50 \mu \mathrm{H} \mathrm{H}_{2} \mathrm{O}$ (RNAse-free). RNA content in the samples was measured at $260 \mathrm{~nm}$ and purity of the samples was determined by the A260/280 ratio and through ethidium bromide fluorescence of RNA resolved in 1\% agarose gels. Samples were also tested in a bioanalyzer 2100B (Agilent Technologies, Santa Clara CA, USA) to determine the RNA Integrity Number (RIN).

\section{Probe Preparation and Hybridization to low density arrays}

The RNA used for the hybridization experiments was purified from a pool of brains taken from four mice from each experimental group. For cDNA synthesis, $10 \mu \mathrm{g}$ of 
total RNA was used as a template, incorporating dUTP-Cy3 or dUTP-Cy5 with the CyScribe First-Strand cDNA labeling kit (Amersham Corp.). Incorporation of the fluorophore was analyzed by evaluating absorbance at $555 \mathrm{~nm}$ for Cy3 and at $655 \mathrm{~nm}$ for Cy5. Array hybridization and washing was performed with a Lucidea Slide Pro (Amersham Corp.) system. Equal amounts of labeled cDNA were hybridized for $14 \mathrm{~h}$ at $42^{\circ} \mathrm{C}$ to the oligo mice arrays in UniHyb hybridization solution (TeleChem International, Inc., Sunnyvale, CA, USA).

\section{Data Acquisition and Analysis of Array Images}

Hybridization data were obtained by using a scanner GenePix 4000B (Axon) and microarray data analysis was performed with the GenArise software, developed by the Computing Unit at the Cellular Physiology Institute of the UNAM (Gómez-Mayen, 2006), as previously described (Rojas-Mayorquin et al., 2008). The software identifies differentially expressed genes by calculating an intensity-dependent z-score. By applying these criteria, the elements with a z-score $>1.5$ standard deviations are genes likely to be differentially expressed.

\section{Reverse transcriptase-PCR}

Total RNA was extracted from hippocampus tissue samples using Trizol reagent, following the manufacturer's instructions. Isolated RNA was treated with amplification grade DNase I for 7 min at room temperature to remove contaminant genomic DNA. First-strand cDNA was reverse transcribed from $2 \mu \mathrm{g}$ of total RNA using a First-Strand Synthesis System kit from Invitrogen. $\beta$-actin primers were designed to cross a large expanse of intronic sequence between exons 2 and 3 of the mouse gene. Primer nonreactivity with contaminating genomic DNA was tested by including controls that omitted the reverse transcriptase enzyme from the cDNA synthesis reaction (RTnegative controls). The lack of primer dimerization or non-specific PCR product bands was also tested.

\section{Real-time PCR quantification using SYBR Green}

Quantification of relative gene expression was performed by real-time quantitative PCR, using the ABI PRISM 7700 Sequence Detection System (Applied Biosystems, Foster City, CA, USA). Real-time PCR was carried out using a SYBR Green PCR kit. Quantitative PCR was carried out using the following thermal cycling program. Stage 1 
was undertaken at $95^{\circ} \mathrm{C}$ for 15 min while stage 2 consisted of the following three steps repeated for 40 cycles: $95^{\circ} \mathrm{C}$ for $15 \mathrm{~s} ; 60^{\circ} \mathrm{C}$ for $30 \mathrm{~s}$; and $72^{\circ} \mathrm{C}$ for $30 \mathrm{~s}$. Relative mRNA expression was calculated by the standard curve method. In brief, $\beta$-actin and target gene amplifications were run in separate tubes. Standard curves were obtained for all genes by using decreasing amounts of cDNA template. PCR reactions were performed in duplicate for standard curves whereas samples were tested in triplicate, at a final volume of $25 \mu \mathrm{l}$ in all cases. For each cDNA template, the cycle threshold $(\mathrm{Ct})$ required to detect the amplified product was determined and semi-logarithmic standard plots were drawn (Ct vs cDNA amount). The calculations were performed based on the $\mathrm{Ct}$ method. This technique uses the formula $2-\Delta \Delta \mathrm{Ct}$ to calculate the expression of target genes normalized to a calibrator ( $\mathrm{N}^{\circ}$ Fold). The $\mathrm{Ct}$ indicates the cycle number in which the amount of amplified target reaches a fixed threshold. The $\mathrm{Ct}$ data for all target and housekeeping genes in each sample were used to establish $\Delta \mathrm{Ct}$ values $[\Delta \mathrm{Ct}=\mathrm{Ct}$ (target gene)-Ct (housekeeping gene)]. In our experiments, $\beta$-actin was used as a reference (housekeeping) gene. Thereafter, $\Delta \Delta \mathrm{Ct}$ values were calculated by subtracting the calibrator from the $\Delta \mathrm{Ct}$ value of each target. The relative quantity (RQ), or $\mathrm{N}^{\circ}$ fold, was calculated using the equation $\mathrm{RQ}=2-\Delta \Delta \mathrm{Ct}$ (Livak et al., 2001). Real-time RT-PCR data were quantified using the SDS 2.2 software package.

\section{Statistical analysis}

Data are expressed as the mean \pm S.E.M. from at least eight samples. In all cases, data were analyzed by ANOVA followed by post-hoc Tukey-Kramer multiple-comparison tests. $P$ values lower than 0.05 were considered significant.

\section{RESULTS}

At the end of the experimental protocol, the different experimental groups registered no significant changes in weight gain (data not shown). Weekly control of food intake was performed both in control and IF mice and was on average per week of $35 \mathrm{~g}$ and $28 \mathrm{~g}$, respectively.

Microarray analysis were performed in order to simultaneously analyze the expression of several genes involved in signaling pathways related to oxidative stress, 
mitochondrial-related apoptosis, cell cycle proteins, sirtuin family, and other proteins associated with neurologic diseases, cell structure and general cell processes. Total of 62 genes were tested and the resultant $\mathrm{z}$-scores were obtained from four independent experiments each performed in duplicate. Table 1 shows the list of genes included in teh array and difference in levels of gen expression (z-score) between the control SAMP8 and SAMR1, whereas Table 2 shows the list of genes included in the array and differences in levels of gene score (z-score) between the SAMP8 and SAMP8 mice. Although the analysis software establishes that a z-score over 1.5 indicates a possible differentially expressed gene, on the basis of previous analysis (Rojas-Mayorquin et al., 2008) we considered only those genes with z-score over 2.0 as significant for further analysis. After cross analysis, none of the genes exceeded this value in any of the comparisons performed. However, we found some genes with a $\mathrm{z}$-score of between 1.5 and 2.0 (see tables 1 and 2). For instance, in SAMP8 mice three genes exceeded a $\mathrm{z}$ score of 1.5: Rb1 (-1.95), Casp9 (-1.65) and Park2 (-1.50) compared with SAMR1 mice (Table 1). On the other hand, in SAMP8 mice the expression of Gpx1 (-1.89), Jun (1.76) and E2f1 (-1.57) were reduced and that of App increased (1.61) after intermittent fasting (Table 2). Therefore, at least at transcription level, non-significant modifications in the genes tested were induced by IF in the SAMP8 model under our experimental strategy.

As show in Fig 1A the conventional RT-PCR analysis showed a lower sirtuin 1 gene expression in IF-SAMP8 mice compared with IF-SAMP8 mice. Sirtuin 1 expression was lower in the cortex of SAMP8 than SAMR1 mice, but intermittent fasting partially recovered the sirtuin 1 protein levels of the IF-SAMP8 mice (Fig 1B). Similar results were obtained for the hippocampus (Data not shown). SAMP8 presented higher acetylated NFKB than SAMR1 mice. IF induced a decrease in the acetylated form of this transcription factor in SAMR1 and SAMP8. With respect to FoxO1, immunoprecipitation studies of this transcription factor indicated that, in non-fasted SAMP8 mice, the acetylated form of FoxO1 was significantly greater in SAMP8 than in SAMR1, while SAMP8 mice on the IF regimen showed a significant reduction of Ac-FoxO1 (Fig 2B).

As a measure of the neuroprotective effect of IF in ageing, we chose two well-known markers of survival, namely the neurotrophic factor BDNF and HSP70, a marker of 
neuronal survival. The expression of BDNF in SAMP8 was lower than in SAMR1 mice. However, there was a significant increase in BDNF levels in IF-SAMP8 micecompared to SAMP8 mice (Fig 3A). In our experimental conditions, samples from SAMP8 micedisplayed lower HSP70 expression than in SAMR1 mice. A significant recovery in HSP70 expression was noted in IF-SAMP8mice compared with SAMP8 mice, yielding similar values to SAMR1 mice(Fig 3B).

In reference to hallmark proteins of $\mathrm{AD}$, we studied the expression of p-tau Ser ${ }^{199}$, pGSK3ß $\mathrm{Tyr}^{216}$ and ADAM10. A significant reduction in tau hyperphosphorylation in IF-SAMP8 was detected in comparison to SAMP8 mice (Fig. 4A). Accordingly, IF induced a decrease in $\mathrm{p}$-GSK3B $\mathrm{Tyr}^{216}$, which represents the active form of this kinase (Fig. 3A). SAMP8 mice had a significantly lower expression of ADAM10 compared to SAMR1 mice; however, the expression of this protein was recovered in IF-SAMP8 mice(Fig 4B).

In addition, we studied p-FoxO1 and p-JNK as indicators of neurodegenerative processes. No changes were observed in IF-SAMR1 mice compared with SAMR1mice, but a significant variation in p-FoxO1 and p-JNK was detected between IF-SAMP8 mice and SAMP8 mice(Fig 5), similarly to levels displayed in SAMR1 mice.

\section{DISCUSSION}

Restricted calorie intake ameliorates senescence-related diseases such as $\mathrm{AD}$ and metabolic syndrome in several systems and experimental models, including humans. Moreover, increasing evidence from studies of human populations suggests that overeating and diabetes increase the risk of AD (Janson et al., 2004; Launer, 2005; Luchsinger et al., 2004; Ott et al., 1999), and that low calorie diets reduce those risks (Luchsinger et al., 2002). One variation of restricted calorie intake is intermittent fasting (IF), an experimental strategy that has some similarities to calorie reduction and is widely used to study the effects of a reduced calorie intake on organisms (Halagappa et al., 2007).

In current studies, non-significant changes were found in the transcriptional activity of the 62 genes tested. In contrast, at a phenotypic level, we found that IF ameliorated ptau Ser ${ }^{199}$ expression in SAMP8 (Canudas et al., 2005; Tajes et al., 2008), as well as 
other neurodegenerative hallmarks of this strain, such as p-GSK3ß $\mathrm{Tyr}^{216}$, p-FoxO1 and p-JNK expression (Tajes et al., 2009a). Our result corroborate the protective role of IF in this murine model, as shown by indirect markers of neuroprotection such as the higher expression of BDNF and HSP70 in IF mice (Lee et al., 2000).

Our study focused on the sirtuin 1 pathway, one of the signalling cascades implicated in the protective process. Sirtuin 1 belongs to a nicotinamide adenine dinucleotide $(\mathrm{NAD})^{+}$-dependent protein deacetylase family of ontogenically well-conserved molecules. Sirtuin family members regulate not only gene silencing, DNA repair, and rDNA recombination, but also ageing, and apoptosis (Grubisha et al., 2005; Michan et al., 2007). In this context, increased sirtuin 1 expression protects cells against A $\beta$ induced reactive oxygen species (ROS) production and DNA damage, thereby reducing apoptotic death in vitro (Alcendor et al., 2004;Kim et al., 2007). Moreover, in AD, neurons are rescued by the over-expression of sirtuin 1 induced by either CR (Mattson, 2000) or the administration of resveratrol (Vingtdeux et al., 2008), a potential activator of this enzyme.

SAMP8 show low sirtuin 1 expression and a reduced activation of this deacetylase with age (Pallas et al., 2008; Gutierrez-Cuesta et al., 2008). Accordingly, a significant reduction in sirtuin 1 activity in SAMP8 was observed in comparison to SAMR1. Interestingly, IF-SAMP8 presented an increase in sirtuin 1 expression, which reached SAMR1 values. However, we detected a slight reduction in sirtuin 1 gene expression after IF in SAMP8. It has also been described that the rise in sirtuin 6 protein expression after calorie restriction is caused by an increase in the stability of the protein and not enhanced transcription (Kanfi et al., 2008b). Recently, the same authors demonstrated that the increase in sirtuin 1 expression after fasting in mice is also due to the stabilization of protein,not an increase due to sirtuin 1 mRNA (Kanfi et al., 2008a). Our findings show that IF increases sirtuin 1 protein expression and reduces the mRNA levels in SAMP8 mice, indicating a stabilization of protein after a reduction in food intake.

In accordance with previous results (Gutierrez-Cuesta et al., 2008), SAMP8 mice presented higher acetylated NFKB than SAMR1 mice. As a result of the increase in sirtuin 1 protein expression, some of the protein's targets, such as NFKB or FoxO1, were more deacetylated in IF-SAMP8 than in control SAMP8 mice. These results 
correlate with an increase in pro-survival signals or factors, such as BDNF or HSP70. The relationship between BDNF, HSP70 and sirtuin 1 has been described in several neuronal systems. For example, neurotrophic factors protect neurons in several experimental models of neurodegenerative disorders. Moreover, the expression of several neurotrophic factors, the most notable of which is BDNF, increases in the brain of rats and mice on a calorie restriction regimen (Duan et al., 2001; Lee et al., 2000) while infusion of a BDNF blocking antibody into the lateral ventricles of rats on a restricted diet significantly attenuates the protective effect (Lee et al., 2002).

SAMP8 mice display a reduction in ADAM10 expression concomitantly with an increase in oligomeric amyloid deposition in the brain. After IF, the ADAM10 protein increased in SAMP8 mice, thereby corroborating the previously described relationship between sirtuin 1 and ADAM10 through mechanisms involving the regulation of the serine/threonine Rho kinase ROCK1 (Qin et al., 2006a). Firm evidence of this relationship was obtained when Patel (Patel et al., 2005) showed that short-term calorie restriction substantially decreased the accumulation of $A B$ plaques in two $A D$-prone APP/presenilin transgenic mouse lines, and decreased the presence of gliosis marked by astrocytic activation. In another study, Qin and colleagues (Qin et al., 2006b) showed that a restricted dietary regimen prevents $A ß$ peptide generation and neuritic plaque deposition in the brain of another AD mouse model ( $\mathrm{Tg} 2576$ mice). In a recent report, the same group showed that calorie restriction results in reduced $A B$ content in the temporal cortex of squirrel monkeys, in a manner that was inversely correlated with sirtuin 1 protein concentrations in the same brain region (Qin et al., 2006a).

To ascertain the beneficial effects of IF in SAMP8, we studied several apoptotic pathways in this senescence model. Among other cellular systems controlling senescence, we examined JNK and FoxO1 signaling by phosphorylation because these transcription factors are implicated in cellular demise. In the present study, we demonstrate that IF in SAMP8 recovery the phosphorylated levels of these two factors to SAMR1, thereby indicating that an IF regimen promotes a neuroprotective effect, which is possibly additive to sirtuin 1 activation. In addition, IF results in a decrease in GSK3ß activation and tau phosphorylation in SAMP8, hence possibly reducing neurofibrilar tangle formation and neuronal death, as described elsewhere (Tajes et al., 2008; Canudas et al., 2005). 
In conclusion, IF activated the sirtuin 1 pathway, a critical signaling cascade involved in longevity and cellular health in the senescence-accelerated model used in this study. Moreover, this dietary regimen reduced some of the death signals implicated in neuronal death and ageing processes. These findings corroborate the results of other authors using distinct animal senescence models or other dietary/pharmacological strategies to activate the sirtuin 1 pathway. Our data indicate that dietary strategies or the modulation of the cellular system could provide potential approaches to slow the ageing process, thereby reducing frailty and improving health in old age.

\section{ACKNOWLEDGEMENTS}

We thank the Language Advisory Service of the University of Barcelona for revising the manuscript. This study was supported by grants SAF-2009-13093 from the "Ministerio de Educación y Ciencia", PI080400 from the "Instituto de Salud Carlos III", 2009/SGR00893 from the "Generalitat de Catalunya" and 0310 from the "Fundació La Marató de TV3".

\section{REFERENCES}

1.Alcendor, R. R., Kirshenbaum, L. A., Imai, S., Vatner, S. F., Sadoshima, J. 2004. Silent information regulator 2alpha, a longevity factor and class III histone deacetylase, is an essential endogenous apoptosis inhibitor in cardiac myocytes. Circ.Res. 95, 971-980.

2.Calabrese, V., Cornelius, C., Mancuso, C., Pennisi, G., Calafato, S., Bellia, F., Bates, T. E., Giuffrida Stella, A. M., Schapira, T., Ankova Kostova, A. T., Rizzarelli, E. 2008. Cellular stress response: a novel target for chemoprevention and nutritional neuroprotection in aging, neurodegenerative disorders and longevity. Neurochem.Res. 33, 2444-2471.

3.Canudas, A. M., Gutierrez-Cuesta, J., Rodriguez, M. I., Acuna-Castroviejo, D., Sureda, F. X., Camins, A., Pallas, M. 2005. Hyperphosphorylation of microtubule-associated protein tau in senescence-accelerated mouse (SAM). Mech.Ageing Dev. 126, 1300-1304. 
4.Duan, W., Lee, J., Guo, Z., Mattson, M. P. 2001. Dietary restriction stimulates BDNF production in the brain and thereby protects neurons against excitotoxic injury. J.Mol.Neurosci 16, 1-12.

5.Gómez-Mayen, A. C.-G. G. R.-R. L. C.-C. G. The Package "GenArise" (API) Version 1.7.3 Microarray analysis tool. http://www.ifc.unam.mx/genarise/. 2006.

6.Grubisha, O., Smith, B. C., Denu, J. M. 2005. Small molecule regulation of Sir2 protein deacetylases . FEBS J. 272, 4607-4616.

7.Gutierrez-Cuesta, J., Tajes, M., Jimenez, A., Coto-Montes, A., Camins, A., Pallas, M. 2008. Evaluation of potential pro-survival pathways regulated by melatonin in a murine senescence model. J.Pineal Res. 45, 497-505.

8.Halagappa, V. K., Guo, Z., Pearson, M., Matsuoka, Y., Cutler, R. G., LaFerla, F. M., Mattson, M. P. 2007. Intermittent fasting and caloric restriction ameliorate age-related behavioral deficits in the triple-transgenic mouse model of Alzheimer's disease. Neurobiol.Dis. 26, 212-220.

9.Hipkiss, A. R. 2007. Dietary restriction, glycolysis, hormesis and ageing. Biogerontology. 8, 221-224.

10. Janson, J., Laedtke, T., Parisi, J. E., O'Brien, P., Petersen, R. C., Butler, P. C. 2004. Increased risk of type 2 diabetes in Alzheimer disease. Diabetes 53, 474481.

11. Kanfi, Y., Peshti, V., Gozlan, Y. M., Rathaus, M., Gil, R., Cohen, H. Y. 2008a. Regulation of SIRT1 protein levels by nutrient availability. FEBS Lett. 582, 2417-2423.

12. Kanfi, Y., Shalman, R., Peshti, V., Pilosof, S. N., Gozlan, Y. M., Pearson, K. J., Lerrer, B., Moazed, D., Marine, J. C., de, C. R., Cohen, H. Y. 2008b. Regulation of SIRT6 protein levels by nutrient availability. FEBS Lett. 582, 543-548.

13. Kim, D., Nguyen, M. D., Dobbin, M. M., Fischer, A., Sananbenesi, F., Rodgers, J. T., Delalle, I., Baur, J. A., Sui, G., Armour, S. M., Puigserver, P., Sinclair, D. A., Tsai, L. H. 2007. SIRT1 deacetylase protects against neurodegeneration in models for Alzheimer's disease and amyotrophic lateral sclerosis. EMBO J. 26, 3169-3179.

14. Komatsu, T., Chiba, T., Yamaza, H., Yamashita, K., Shimada, A., Hoshiyama, Y., Henmi, T., Ohtani, H., Higami, Y., de, C. R., Ingram, D. K., Shimokawa, I. 
2008. Manipulation of caloric content but not diet composition, attenuates the deficit in learning and memory of senescence-accelerated mouse strain P8. Exp.Gerontol.

15. Launer, L. J. 2005. Diabetes and brain aging: epidemiologic evidence. Curr.Diab.Rep. 5, 59-63.

16. Lee, J., Duan, W., Long, J. M., Ingram, D. K., Mattson, M. P. 2000. Dietary restriction increases the number of newly generated neural cells, and induces BDNF expression, in the dentate gyrus of rats. J.Mol.Neurosci 15, 99-108.

17. Lee, J., Duan, W., Mattson, M. P. 2002. Evidence that brain-derived neurotrophic factor is required for basal neurogenesis and mediates, in part, the enhancement of neurogenesis by dietary restriction in the hippocampus of adult mice. J.Neurochem. 82, 1367-1375.

18. Livak, K. J., Schmittgen, T. D. 2001. Analysis of relative gene expression data using real-time quantitative PCR and the 2(-Delta Delta C(T)) Method. Methods $25,402-408$

19. Luchsinger, J. A., Tang, M. X., Shea, S., Mayeux, R. 2004. Hyperinsulinemia and risk of Alzheimer disease. Neurology 63, 1187-1192.

20. Luchsinger, J. A., Tang, M. X., Shea, S., Mayeux, R. 2002. Caloric intake and the risk of Alzheimer disease. Arch.Neurol. 59, 1258-1263.

21. Martin, B., Mattson, M. P., Maudsley, S. 2006. Caloric restriction and intermittent fasting: two potential diets for successful brain aging. Ageing Res.Rev. 5, 332-353.

22. Mattson, M. P. 2000. Existing data suggest that Alzheimer's disease is preventable. Ann.N.Y.Acad.Sci. 924, 153-159.

23. Mattson, M. P. 2003. Will caloric restriction and folate protect against AD and PD? Neurology 60, 690-695.

24. Mattson, M. P., Duan, W., Chan, S. L., Cheng, A., Haughey, N., Gary, D. S., Guo, Z., Lee, J., Furukawa, K. 2002. Neuroprotective and neurorestorative signal transduction mechanisms in brain aging: modification by genes, diet and behavior. Neurobiol.Aging 23, 695-705.

25. Michan, S., Sinclair, D. 2007. Sirtuins in mammals: insights into their biological function. Biochem.J. 404, 1-13. 
26. Ott, A., Stolk, R. P., van, H. F., Pols, H. A., Hofman, A., Breteler, M. M. 1999. Diabetes mellitus and the risk of dementia: The Rotterdam Study. Neurology 53, 1937-1942.

27. Pallas, M., Pizarro, J. G., Gutierrez-Cuesta, J., Crespo-Biel, N., Alvira, D., Tajes, M., Yeste-Velasco, M., Folch, J., Canudas, A. M., Sureda, F. X., Ferrer, I., Camins, A. Modulation of SIRT1 expression in different neurodegenerative models and human pathologies. Neuroscience. 2008.

28. Patel, N. V., Gordon, M. N., Connor, K. E., Good, R. A., Engelman, R. W., Mason, J., Morgan, D. G., Morgan, T. E., Finch, C. E. 2005. Caloric restriction attenuates Abeta-deposition in Alzheimer transgenic models. Neurobiol.Aging 26, 995-1000.

29. Qin, W., Chachich, M., Lane, M., Roth, G., Bryant, M., de, C. R., Ottinger, M. A., Mattison, J., Ingram, D., Gandy, S., Pasinetti, G. M. 2006a. Calorie restriction attenuates Alzheimer's disease type brain amyloidosis in Squirrel monkeys (Saimiri sciureus). J.Alzheimers.Dis. 10, 417-422.

30. Qin, W., Yang, T., Ho, L., Zhao, Z., Wang, J., Chen, L., Zhao, W., Thiyagarajan, M., MacGrogan, D., Rodgers, J. T., Puigserver, P., Sadoshima, J., Deng, H., Pedrini, S., Gandy, S., Sauve, A. A., Pasinetti, G. M. 2006b. Neuronal SIRT1 activation as a novel mechanism underlying the prevention of Alzheimer disease amyloid neuropathology by calorie restriction. J.Biol.Chem. 281, 2174521754.

31. Rodgers, J. T., Lerin, C., Haas, W., Gygi, S. P., Spiegelman, B. M., Puigserver, P. 2005. Nutrient control of glucose homeostasis through a complex of PGC1alpha and SIRT1. Nature 434, 113-118.

32. Rojas-Mayorquin, A. E., Torres-Ruiz, N. M., Ortuno-Sahagun, D., GudinoCabrera, G. 2008. Microarray analysis of striatal embryonic stem cells induced to differentiate by ensheathing cell conditioned media. Dev.Dyn. 237, 979-994.

33. Salminen, A., Ojala, J., Huuskonen, J., Kauppinen, A., Suuronen, T., Kaarniranta, K. 2008. Interaction of aging-associated signaling cascades: inhibition of NF-kappaB signaling by longevity factors FoxOs and SIRT1. Cell Mol.Life Sci. 65, 1049-1058.

34. Smith, J. 2002. Human Sir2 and the 'silencing' of p53 activity. Trends Cell Biol. $12,404-406$. 
35. Tajes, M., Gutierrez-Cuesta, J., Folch, J., Ferrer, I., Caballero, B., Smith, M. A., Casadesus, G., Camins, A., Pallas, M. 2008. Lithium treatment decreases activities of tau kinases in a murine model of senescence. J.Neuropathol.Exp.Neurol. 67, 612-623.

36. Tajes, M., Yeste-Velasco, M., Zhu, X., Chou, S. P., Smith, M. A., Pallas, M., Camins, A., Casadesus, G. 2009a. Activation of Akt by lithium: pro-survival pathways in aging. Mech.Ageing Dev. 130, 253-261.

37. Takeda, T. 1999. Senescence-accelerated mouse (SAM): a biogerontological resource in aging research. Neurobiol.Aging 20, 105-110.

38. Vingtdeux, V., Dreses-Werringloer, U., Zhao, H., Davies, P., Marambaud, P. 2008. Therapeutic potential of resveratrol in Alzheimer's disease. BMC.Neurosci 9 Suppl 2, S6.

39. Wang, F., Nguyen, M., Qin, F. X., Tong, Q. 2007. SIRT2 deacetylates FOXO3a in response to oxidative stress and caloric restriction. Aging Cell 6, 505-514.

40. Westphal, C. H., Dipp, M. A., Guarente, L. 2007. A therapeutic role for sirtuins in diseases of aging? Trends Biochem.Sci. 32, 555-560.

\section{Figure legends}

Fig 1: (A) Semi-quantitative RT-PCR analysis of sirtuin $1 \mathrm{mRNA}$ in cortex of SAMR1 and SAMP8 mice non-fasted (CT R1 and CT P8) and after intermittent fasting (IF R1 and IF P8). (B) Sirtuin 1 expression in the experimental conditions tested. Sirtuin 1 expression increased in IF-SAMP8 mice compared with SAMP8 mice. Images show representative Western blot and bar graph obtained from semi-quantitative image analysis, as described in Materials and methods. Data represent means \pm SD of 6-8 mice. ***p<0.001 vs. CT R1; \#\#p<0.01 vs. CT P8

Fig 2: Protein expression of Ac-NFkB (A) and Ac-FoxO1 (B) in cortex of SAMR1 and SAMP8 mice non-fasted (CT R1 and CT P8) and after intermittent fasting (IF R1 and IF P8). Results showed that Ac-NFkB and Ac-FoxO1 expression in IF P8 are lower than in CT P8. Images showed representative Western blot and bar graph obtained from semi-quantitative image analysis, as described in Materials and methods. Data 
represent means \pm SD of $6-8$ mice. $* \mathrm{p}<0.05, * * \mathrm{p}<0.01$ and $* * * \mathrm{p}<0.001$ vs. CT R1; $\# \# \#$ p $<0.001$ vs. CT P8.

Fig 3: BDNF and HSP70 expression in cortex of SAMR1 and SAMP8 mice non-fasted (CT R1 and CT P8) and after intermittent fasting (IF R1 and IF P8). (A) BDNF expression in CT P8 was significantly lower than in CT R1. IF treatment restored the expression of this neurotrophic factor. (B) HSP70 presented a similar recovery profile than BDNF after IF in CT P8. Images show representative Western blot and bar graph obtained from semi-quantitative image analysis as mentioned in Materials and methods. Data represent means \pm SD of 6-8 mice. $* * p<0.01$ vs. CT R1; \#p<0.05; \#\#\#p<0.001 vs. CT P8.

Fig 4. (A) The degree of Tau phosphorylation in $\mathrm{Ser}^{199}$ was higher in CT P8 than in IFP8, concomitantly a higher $\mathrm{p}-\mathrm{GSK} 3 \beta \mathrm{Tyr}^{216}$ activation. IF reduced phosphorylations in SAMP-8 (B) ADAM10 levels in CT R1 are higher than in P8. Results showed that IFP8 recovered ADAM10 to CT R1 levels. Images show representative Western blot and bar graph obtained from semi-quantitative image analysis, as described in Materials and methods. Data represent means \pm SD of $6-8$ mice. $* * p<0.01 ; * * * p<0.001$ vs. CT $\mathrm{R} 1 ; \# \# \mathrm{p}<0.01 ; \# \# \# \mathrm{p}<0.001$ vs. CT P8.

Fig. 5. p-FoxO1 and p-JNK expression in cortex of SAMR1 and SAMP8 mice nonfasted (CT R1 and CT P8) and after intermittent fasting (IF R1 and IF P8) (A) Expression of p-FoxO1 in IFP8 was significantly higher than in CT P8. (B) p-JNK showed a reduction in the phosphorylated form in IF compared with CT P8. Images show representative Western blot, and bar graph obtained from semi-quantitative image analysis, as described in Materials and methods. Data represent means \pm SD of 6-8 mice. $* * * \mathrm{p}<0.001$ vs. CT R1; \#\#p<0.01; \#\#\#<<0.001 vs. CT P8 
Tajes et al Figure 1

A

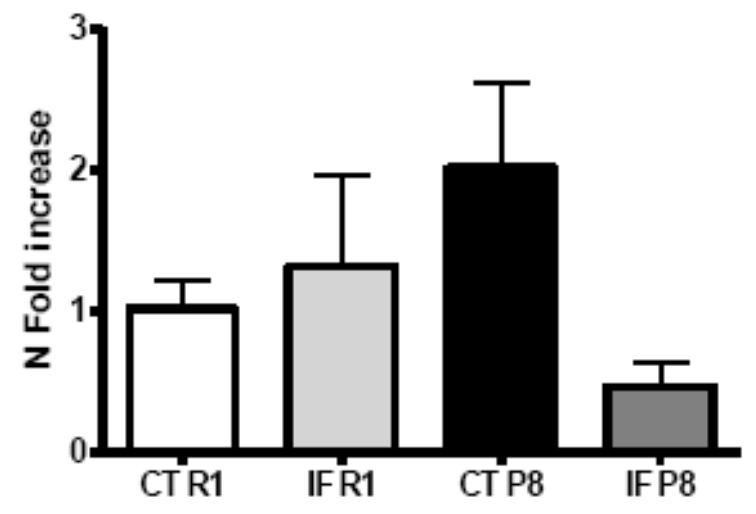

B

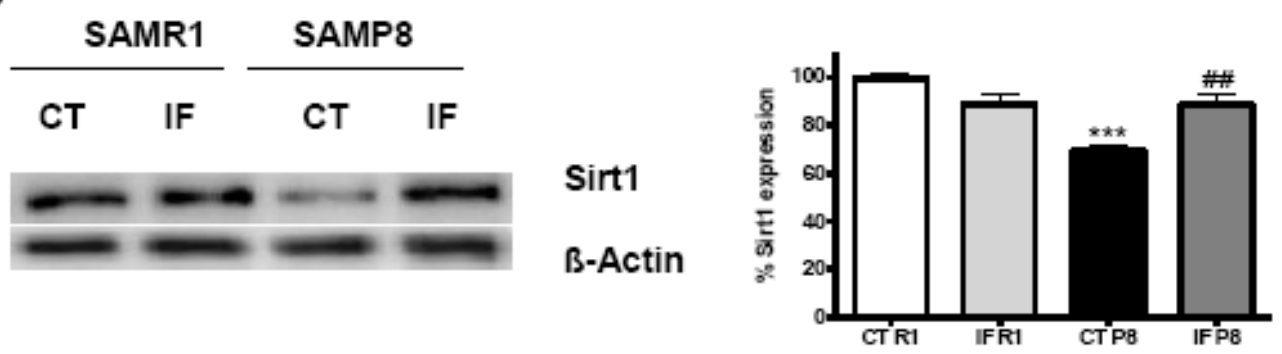


Tajes et al Figure 2

A

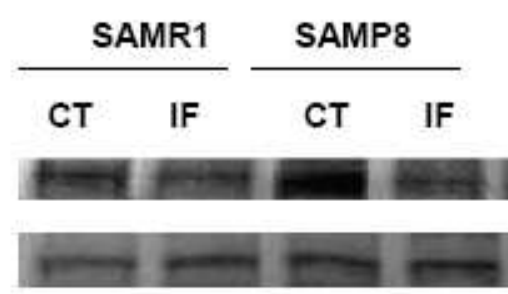

B

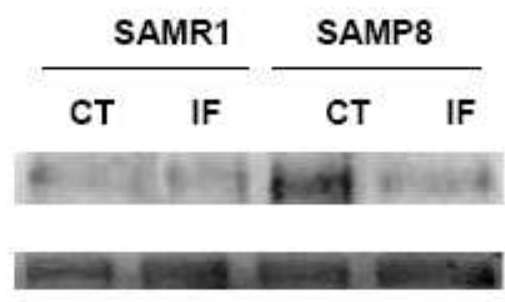

AC-NFkB

Total-NFkB

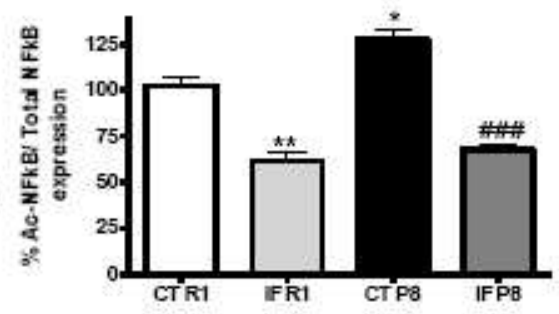

Ac-FoxO1

IP: Fox01

IB:Ac-Lys Ab

Fox01

IP/IB: FoxO1

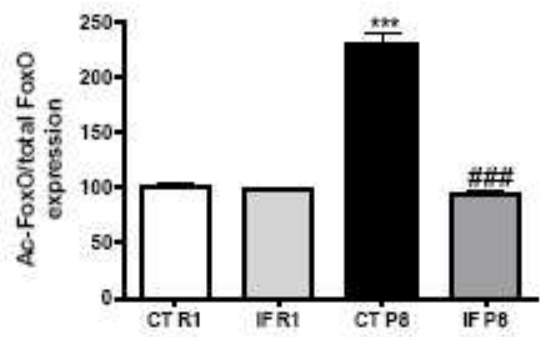


Tajes et al. Figure 3

A

\begin{tabular}{|c|c|c|c|c|}
\hline \multicolumn{2}{|c|}{ SAMR1 } & \multicolumn{2}{|c|}{ SAMP8 } & \\
\hline CT & IF & CT & IF & \\
\hline- & $=$ & -5 & - & BDNF \\
\hline
\end{tabular}

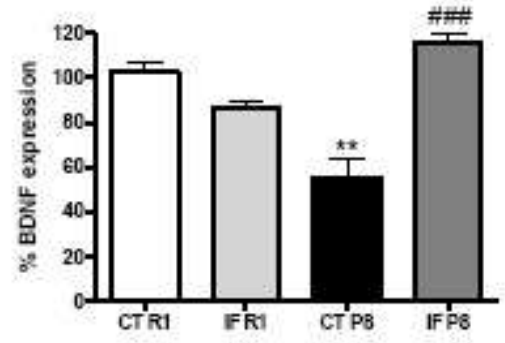

B

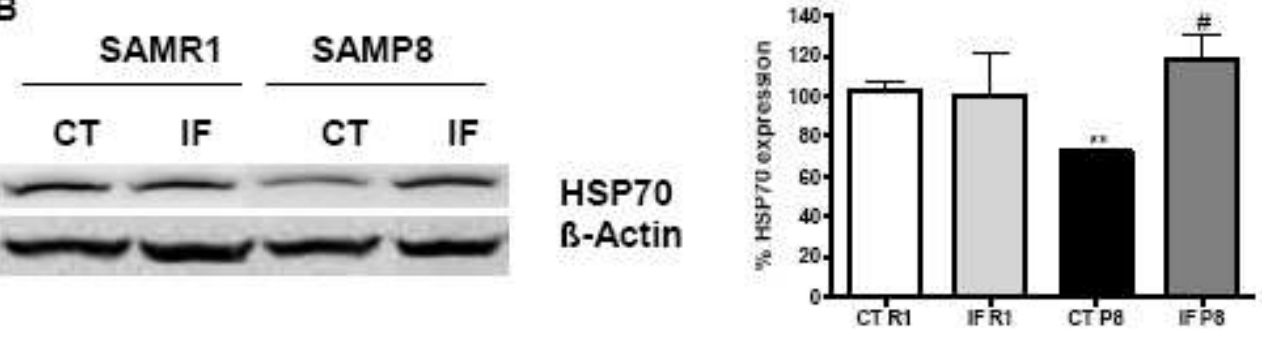


Tajes et al., Figure 4
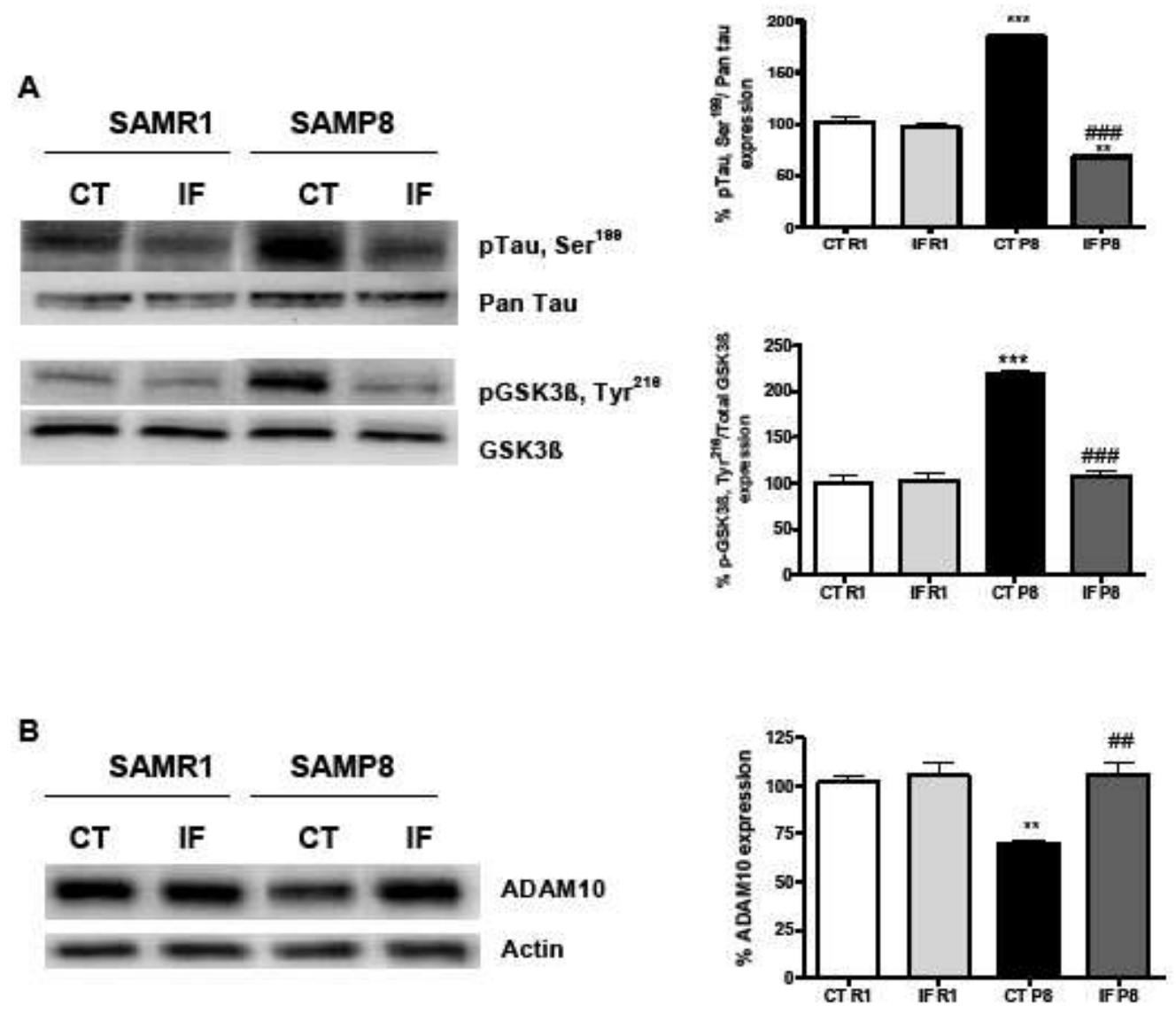
Tajes et al., Figure 5

A
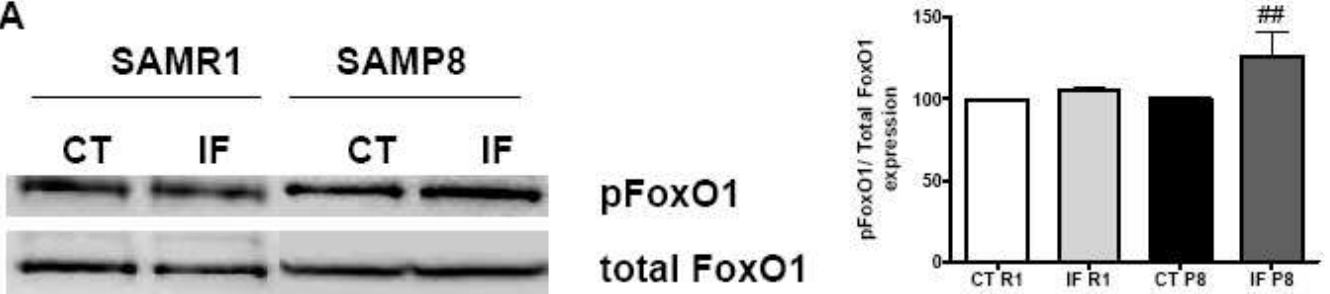

B
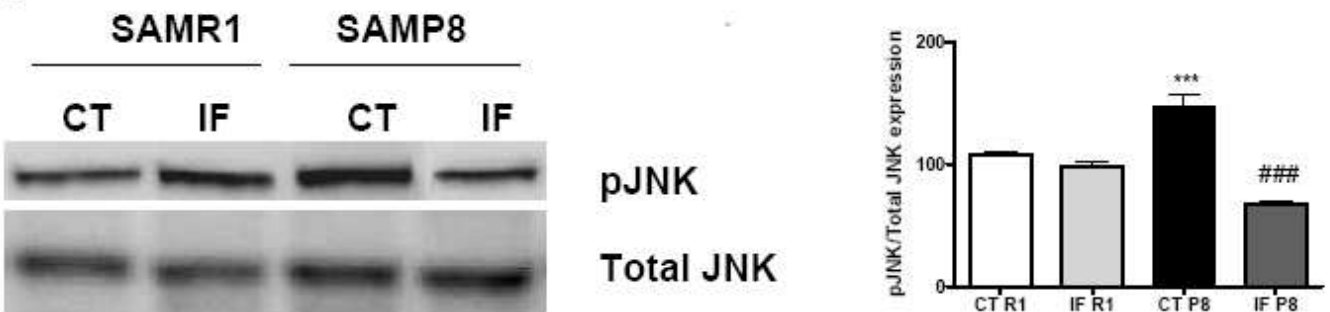
Table 1. List of genes included in the array and z-score of the gen expression levels between SAMP8 and SAMR1. $n . d$. No determined.

\begin{tabular}{|c|c|c|c|c|c|c|c|}
\hline GENE ID & Symbol & Gene name & z-score & GENE ID & Symbol & Gene name & z-score \\
\hline NM_009029 & $\mathrm{Rb} 1$ & retinoblastoma 1 & -1.95 & NM_008084 & Gapdh & $\begin{array}{l}\text { glyceraldehyde-3-phosphate } \\
\text { dehydrogenase }\end{array}$ & 0.00 \\
\hline NM_015733 & Casp9 & caspase 9 & -1.65 & NM_008639 & Mtnr1a & melatonin receptor $1 \mathrm{~A}$ & 0.01 \\
\hline NM_012019 & Aifm1 & $\begin{array}{l}\text { apoptosis-inducing factor, } \\
\text { mitochondrion-associated } 1\end{array}$ & -1.38 & NM_009983 & Ctsd & cathepsin D & 0.11 \\
\hline NM_007631 & Ccnd1 & cyclin D1 & -0.92 & NM_007600 & Capn1 & calpain 1 & 0.22 \\
\hline NM_007471 & App & amyloid beta (A4) precursor protein & -0.90 & NM_001038609 & Mapt & $\begin{array}{l}\text { microtubule-associated protein tau, } \\
\text { transcript variant } 1\end{array}$ & 0.27 \\
\hline NM_009812 & Casp8 & caspase 8 , transcript variant 1 & -0.88 & NM_009656 & Aldh2 & $\begin{array}{l}\text { aldehyde dehydrogenase } 2 \text {, } \\
\text { mitochondrial }\end{array}$ & 0.30 \\
\hline NM_010279 & Gfra1 & $\begin{array}{l}\text { glial cell line derived neurotrophic factor } \\
\text { family receptor alpha } 1\end{array}$ & -0.57 & NM_013671 & Sod2 & superoxide dismutase 2, mitochondrial & 0.34 \\
\hline NM_009871 & Cdk5r1 & $\begin{array}{l}\text { cyclin-dependent kinase 5, regulatory } \\
\text { subunit (p35) } 1\end{array}$ & -0.53 & NM_007628 & Ccna1 & cyclin A1 & 0.34 \\
\hline NM_011949 & Mapk1 & $\begin{array}{l}\text { mitogen activated protein kinase } 1, \\
\text { transcript }\end{array}$ & -0.44 & NM_007527 & Bax & Bcl2-associated $\mathrm{X}$ protein & 0.38 \\
\hline NM_011045 & Pcna & proliferating cell nuclear antigen & -0.42 & NM_025735 & Map1lc3 & $\begin{array}{l}\text { microtubule-associated protein } 1 \text { light } \\
\text { chain } 3 \text { alpha }\end{array}$ & 0.43 \\
\hline NM_007545 & Hrk & $\begin{array}{l}\text { harakiri, BCL2 interacting protein } \\
\text { (contains only BH3 domain) }\end{array}$ & -0.41 & NM_007668 & Cdk5 & cyclin-dependent kinase 5 & 0.46 \\
\hline NM_008730 & Nptx1 & neuronal pentraxin 1 & -0.39 & NM_010065 & Dnm1 & dynamin 1 & 0.47 \\
\hline
\end{tabular}




\begin{tabular}{|c|c|c|c|c|c|c|c|c|}
\hline NM_019740 & Foх03a & forkhead box 03a & -0.38 & & NM_009810 & Casp3 & caspase 3 & 0.50 \\
\hline NM_009804 & Cat & catalase & -0.35 & & NM_010362 & Gsto1 & glutathione S-transferase omega 1 & 0.50 \\
\hline NM_019639 & Ubc & ubiquitin $\mathrm{C}$ & -0.31 & & NM_178848 & Sirt5 & $\begin{array}{l}\text { sirtuin } 5 \text { (silent mating type information } \\
\text { regulation } 2 \text { homolog) } 5\end{array}$ & 0.52 \\
\hline NM_022432 & Sirt2 & $\begin{array}{l}\text { sirtuin } 2 \text { (silent mating type information } \\
\text { regulation 2, homolog) } 2\end{array}$ & -0.30 & & NM_011144 & Ppara & $\begin{array}{l}\text { peroxisome proliferator activated } \\
\text { receptor alpha }\end{array}$ & 0.59 \\
\hline NM_133828 & Creb1 & $\begin{array}{l}\text { cAMP responsive element binding } \\
\text { protein } 1 \text {, transcript variant A }\end{array}$ & -0.25 & & NM_011640 & Trp53 & transformation related protein 53 & 0.62 \\
\hline NM_019827 & Gsk3b & glycogen synthase kinase 3 beta & -0.20 & & NM_009050 & Ret & ret proto-oncogene, transcript variant 2 & 0.64 \\
\hline NM_019812 & Sirt1 & $\begin{array}{l}\text { sirtuin } 1 \text { (silent mating type information } \\
\text { regulation 2, homolog) } 1\end{array}$ & -0.17 & & NM_007544 & Bid & $\mathrm{BH} 3$ interacting domain death agonist & 0.66 \\
\hline NM_008160 & Gpx1 & glutathione peroxidase 1 & -0.15 & & NM_019467 & Aif1 & allograft inflammatory factor 1 & 0.67 \\
\hline NM_010344 & Gsr & glutathione reductase 1 & -0.15 & & NM_011952 & Mapk3 & Mitogen activated protein kinase 3 & 0.71 \\
\hline XM_991632 & Sirt4 & $\begin{array}{l}\text { sirtuin } 4 \text { (silent mating type information } \\
\text { regulation } 2 \text { homolog) } 4\end{array}$ & -0.10 & & NM_153056 & Sirt7 & $\begin{array}{l}\text { sirtuin } 7 \text { (silent mating type information } \\
\text { regulation 2, homolog) } 7\end{array}$ & 0.90 \\
\hline NM_022433 & Sirt3 & $\begin{array}{l}\text { sirtuin } 3 \text { (silent mating type information } \\
\text { regulation 2, homolog) } 3\end{array}$ & -0.05 & & NM_007499 & Atm & $\begin{array}{l}\text { ataxia telangiectasia mutated homolog } \\
\text { (human) }\end{array}$ & n.d \\
\hline NM_009794 & Capn2 & calpain 2 & -0.03 & & NM_010275 & Gdnf & glial cell line derived neurotrophic factor & n.d \\
\hline NM_009652 & Akt1 & thymoma viral proto-oncogene 1 & -0.02 & & NM_010591 & Jun & Jun oncogene & n.d \\
\hline NM_009463 & Ucp1 & $\begin{array}{l}\text { uncoupling protein } 1 \text { (mitochondrial, } \\
\text { proton carrier) }\end{array}$ & -0.02 & & NM_001025074 & Ntrk2 & $\begin{array}{l}\text { neurotrophic tyrosine kinase, receptor, } \\
\text { type } 2 \text {, transcript variant } 1\end{array}$ & n.d \\
\hline
\end{tabular}


Table 2. List of genes included in the array and z-score of the gen expression levels between CT SAMP8 and IF SAMP8.

\begin{tabular}{|c|c|c|c|c|c|c|c|}
\hline GENE ID & Symbol & Gene name & $\begin{array}{c}\text { z- } \\
\text { score }\end{array}$ & GENE ID & Symbol & Gene name & $\begin{array}{c}\text { z- } \\
\text { score }\end{array}$ \\
\hline NM_008160 & Gpx1 & glutathione peroxidase 1 & -1.89 & NM_009463 & Ucp1 & $\begin{array}{l}\text { uncoupling protein } 1 \text { (mitochondrial, } \\
\text { proton carrier) }\end{array}$ & -0.03 \\
\hline NM_010591 & Jun & Jun oncogene & -1.76 & NM_019467 & Aif1 & allograft inflammatory factor 1 & -0.03 \\
\hline NM_007891 & E2f1 & E2F transcription factor 1 & -1.57 & NM_009794 & Capn2 & calpain 2 & 0.02 \\
\hline NM_011045 & Pcna & proliferating cell nuclear antigen & -0.84 & NM_022433 & Sirt3 & $\begin{array}{l}\text { sirtuin } 3 \text { (silent mating type } \\
\text { information regulation 2, homolog) } 3\end{array}$ & 0.03 \\
\hline NM_010275 & Gdnf & glial cell line derived neurotrophic factor & -0.78 & NM_019639 & Ubc & ubiquitin $\mathrm{C}$ & 0.12 \\
\hline NM_007631 & Ccnd1 & cyclin D1 & -0.67 & NM_009804 & Cat & catalase & 0.13 \\
\hline NM_009871 & Cdk5r1 & $\begin{array}{l}\text { cyclin-dependent kinase 5, regulatory } \\
\text { subunit (p35) } 1\end{array}$ & -0.57 & NM_013671 & Sod2 & $\begin{array}{l}\text { superoxide dismutase } 2, \\
\text { mitochondrial }\end{array}$ & 0.13 \\
\hline NM_012019 & Aifm1 & $\begin{array}{l}\text { apoptosis-inducing factor, } \\
\text { mitochondrion-associated } 1\end{array}$ & -0.56 & NM_001038609 & Mapt & $\begin{array}{l}\text { microtubule-associated protein tau, } \\
\text { transcript variant } 1\end{array}$ & 0.17 \\
\hline NM_007393 & Actb & actin, beta, cytoplasmic & -0.48 & NM_009810 & Casp3 & caspase 3 & 0.21 \\
\hline NM_181586 & Sirt6 & $\begin{array}{l}\text { sirtuin } 6 \text { (silent mating type information } \\
\text { regulation } 2 \text {, homolog) } 6\end{array}$ & -0.47 & NM_010065 & Dnm1 & dynamin 1 & 0.22 \\
\hline NM_025735 & Map1lc3 & $\begin{array}{l}\text { microtubule-associated protein } 1 \text { light } \\
\text { chain } 3 \text { alpha }\end{array}$ & -0.47 & NM_007668 & Cdk5 & cyclin-dependent kinase 5 & 0.24 \\
\hline NM_015733 & Casp9 & caspase 9 & -0.41 & NM_008639 & Mtnr1a & melatonin receptor $1 \mathrm{~A}$ & 0.24 \\
\hline NM_010362 & Gsto1 & glutathione S-transferase omega 1 & -0.35 & NM_011952 & Mapk3 & Mitogen activated protein kinase 3 & 0.27 \\
\hline NM_019739 & Foxo1 & forkhead box 01 & -0.34 & NM_178848 & Sirt5 & $\begin{array}{l}\text { sirtuin } 5 \text { (silent mating type } \\
\text { information regulation } 2 \text { homolog) } 5\end{array}$ & 0.31 \\
\hline NM_009870 & Cdk4 & cyclin-dependent kinase 4 & -0.33 & NM_019584 & Becn1 & beclin 1 & 0.31 \\
\hline NM_133828 & Creb1 & $\begin{array}{l}\text { CAMP responsive element binding } \\
\text { protein } 1 \text {, transcript variant } A\end{array}$ & -0.30 & NM_008730 & Nptx1 & neuronal pentraxin 1 & 0.32 \\
\hline NM_007545 & Hrk & $\begin{array}{l}\text { harakiri, BCL2 interacting protein } \\
\text { (contains only BH3 domain) }\end{array}$ & -0.23 & NM_007628 & Ccna1 & cyclin A1 & 0.43 \\
\hline
\end{tabular}




\begin{tabular}{|l|l|l|l|} 
NM_008084 & Gapdh & $\begin{array}{l}\text { glyceraldehyde-3-phosphate } \\
\text { dehydrogenase }\end{array}$ & -0.18 \\
\hline NM_007600 & Capn1 & calpain 1 & -0.16 \\
\hline NM_019740 & Fox03a & forkhead box 03a & -0.16 \\
\hline NM_009812 & Casp8 & caspase 8, transcript variant 1 & -0.15 \\
\hline NM_009983 & Ctsd & cathepsin D & -0.14 \\
\hline NM_153056 & Sirt7 & $\begin{array}{l}\text { sirtuin 7 (silent mating type information } \\
\text { regulation 2, homolog) 7 }\end{array}$ & -0.13 \\
\hline NM_007527 & Bax & Bcl2-associated X protein & -0.12 \\
\hline NM_010344 & Gsr & glutathione reductase 1 & -0.10 \\
\hline NM_0010250 & Ntrk2 & $\begin{array}{l}\text { neurotrophic tyrosine kinase, receptor, } \\
\text { type 2, transcript variant 1 }\end{array}$ & -0.09 \\
\hline XM_991632 & Sirt4 & $\begin{array}{l}\text { sirtuin 4 (silent mating type information } \\
\text { regulation 2 homolog) 4 }\end{array}$ & -0.08 \\
\hline NM_009029 & Rb1 & retinoblastoma 1 & -0.08 \\
\hline NM_019827 & Gsk3b & glycogen synthase kinase 3 beta & -0.07 \\
\hline NM_009656 & Aldh2 & $\begin{array}{l}\text { aldehyde dehydrogenase 2, } \\
\text { mitochondrial }\end{array}$ & -0.06 \\
\hline NM_022432 & Sirt2 & $\begin{array}{l}\text { sirtuin 2 (silent mating type information } \\
\text { regulation 2, homolog) 2 }\end{array}$ & -0.05 \\
\hline
\end{tabular}

\begin{tabular}{|l|l|l|c|} 
NM_010279 & Gfra1 & $\begin{array}{l}\text { glial cell line derived neurotrophic } \\
\text { factor family receptor alpha 1 }\end{array}$ & 0.44 \\
\hline NM_007544 & Bid & BH3 interacting domain death agonist & 0.45 \\
\hline NM_016694 & Park2 & parkin & 0.50 \\
\hline NM_009652 & Akt1 & thymoma viral proto-oncogene 1 & 0.54 \\
\hline NM_011949 & Mapk1 & $\begin{array}{l}\text { mitogen activated protein kinase 1, } \\
\text { transcript }\end{array}$ & 0.56 \\
\hline NM_183417 & Cdk2 & $\begin{array}{l}\text { cyclin-dependent kinase 2 transcript } \\
\text { variant 1 }\end{array}$ & 0.56 \\
\hline NM_007499 & Atm & $\begin{array}{l}\text { ataxia telangiectasia mutated } \\
\text { homolog (human) }\end{array}$ & 0.57 \\
\hline NM_011144 & Ppara & $\begin{array}{l}\text { peroxisome proliferator activated } \\
\text { receptor alpha }\end{array}$ & 0.58 \\
\hline NM_019812 & Sirt1 & $\begin{array}{l}\text { sirtuin 1(silent mating type } \\
\text { information regulation 2, homolog) 1 }\end{array}$ & 0.67 \\
\hline NM_011640 & Trp53 & transformation related protein 53 & 1.07 \\
\hline NM_007471 & App & amyloid beta (A4) precursor protein & 1.61 \\
\hline NM_009875 & Cdkn1b & cyclin-dependent kinase inhibitor 1B & n.d \\
\hline NM_007614 & Ctnnb1 & $\begin{array}{l}\text { catenin (cadherin associated protein), } \\
\text { beta 1 }\end{array}$ & n.d \\
\hline NM_009050 & Ret & $\begin{array}{l}\text { ret proto-oncogene, transcript variant } \\
\text { 2 }\end{array}$ & n.d \\
\hline
\end{tabular}

